www.jmscr.igmpublication.org

Impact Factor 5.244

Index Copernicus Value: 83.27

ISSN (e)-2347-176x ISSN (p) 2455-0450

crossref DOI:_http://dx.doi.org/10.18535/jmscr/v4i8.38

\title{
Molecular Study of Methicillin Resistant Staphylococcus aureus Isolated from Different Hospitals in Najaf-Iraq
}

\author{
Authors
}

\author{
Prof. Dr Kareem Thamir Al-kaabi ${ }^{1}$, Dr Thikra Abid Jaber Al-Kashwan ${ }^{2}$, \\ Hala Ridha Al-Fahham ${ }^{3}$ \\ ${ }^{1}$ Professor of microbiology, College of Medicine, Kufa University \\ ${ }^{2}$ Lecturer in Molecular Biology, College of medicine, Kufa University \\ ${ }^{3} \mathrm{MSc}$, Student, Department of Microbiology, College of Medicine, Kufa University \\ Email:hkrooz7@yahoo.com
}

\begin{abstract}
Aim of Study: The aim is to do molecular characterization of Staphylococcus aureus isolated from hospital staff and environment, in order to determine the gene(s) that is (are) responsible for antibiotics resistance especially mecA and SCCmec.

Methodology: This study that aimed to detect methicillin resistant Staphylococcus aureus in isolates from AlSader Teaching Hospital and al-Hakeem General Hospital in Annajaf during the period from November 2015 to April 2016. From a total of 250 clinical samples that were collected to isolate Staphylococcus aureus from the hospital staff (nurses, doctors, workers, medical student---etc.), and also from different parts of hospital environments. A total of 50 Staphylococcus aureus isolate were detected and confirmed by different morphological and biochemical confirmatory test.

Results: These 50 isolates then studied by VITEC 2 and also by cefoxitin disc susceptibility test.It was able to detect only 41 isolates that had cefoxitin resistance which represented $82 \%$ of the total Staphylococcus isolates which are regarded as Methicillin Resistant Staphylococcus aureus phenotypically. Polymerase chain reaction test was done to find out the genes that are responsible for methicillin resistance in these isolates, using three types of primers one was for Sa442 gene which was designed to confirm that the isolates were Staphylococcus aureus and two other genes to confirm that the isolates were methicillin resistant which were mecA and SCCmec with the different subtypes of the last gene, and it was found that from the 41 isolates which were phenotypically confirimed to be methicillin resistant only 32 were found to harbor these genes which represented only $78 \%$ of the phenotypically confirmed MRSA; It was found also that the subtype SCCmec type IV was the most dominant gene among SCCmec types in these isolates as it was detected in 23 out of 32 isolates (71.9\%), followed by SCCmec type III Which was found in 5(15.6\%) of the isolates.

Conclusions: Polymerase chain reaction is the golden slandered for identification of methicillin resistant Staphylococcus aureus MRSA. The SCC mec type IV was the most dominant among SCCmec genotypes of MRSA strains that were isolated from hospitals in the present study.

Recommandation: Vancomycin resistant staphylococcus aureas (VRSA) should be taken in consideration when we are working with hospital cross infection. Further studies on large scale should be performed in order to study MRSA in the whole country. Antibiotic prescribing policy should be put under observation and guidenece inside and outside hospitals.
\end{abstract}

Keywords: staphylococcus aureus, cefoxitin, SCCmec, mecA. 


\section{INTRODUCTION}

Staphylococcus aureus is an important pathogen in causing many diseases like pulmonary infections. Septicemia, cutaneous diseases, bones and heart, in addition to other diseases caused by it's toxins as food poisoning; and shocks ${ }^{(1)}$. Staphylococcus aureus is also a leading cause of nosocomial infections. This bacteria acquires resistance to many antibacterial agents that cause it's therapy difficult. Especially methicillin-resistant Staphylococcus aureus (MRSA) which become a troublesome bacteria for huge number of infections, the hospital acquire one is the most important ${ }^{(2)}$.

Methicillin-susceptible Staphylococcus aureus (MSSA) acquires this phenomenon by gaining some additional gene elements inserted into it's genome. This element is called staphylococcal chromosomes casset SCCmec, which is composed of the, mecA. (3). Certain situations are blamed in the acquisition of MRSA in hospitals like the antibiotics wide use, and many procedures and ecological factors. In man, colonization of Staphylococcus aureus is appeared in the nasal passages. Nasal passage acquisition of Staphylococcus aureus in hospital personnel gives a risk of infection in patients admitted to hospitals. and elimination of this risk factor is found to reduce in the incidence of Staphylococcus aureus infections ${ }^{(4) .}$

\section{MATERIALS AND METHODS}

The study had been done in accordance with recommendation and ethical guidelines of the College of Medicine, Kufa University.

The present study was done without involving any biological materials or genetically modified organisms. A total of 250 clinical samples were taken from both the hospital staff (50 samples) and the hospitals environments (Al-Hakeem and Al-Sader) (200samples).

The staff samples were taken from the anterior nares of persons who were working in different departments of the hospitals. The hospital environmental samples were taken from: hospital air current (80 samples), hospital surfaces( like door handles, floor, beds, 35 samples), hospital instruments like medical equipments, surgical theater lamp(lights), stethoscopes( 85 samples.)

From the 50 hospital staff samples 11 Staphylococcus aureus isolates could be detected, while from the 35 hospital surface samples, 8 Staphylococcus aureus isolates were detected, and from the 80 air current samples of hospital 17 Staphylococcus aureus isolates were detected, while there were 14 Staphylococcus aureus isolates detected from the 85 hospital instrument samples .

All isolates then were confirmed by biochemical and enzymatic confirmative tests and finally by VITEC2 tests then subjected for PCR study.

\section{RESULT AND DISCUSSION}

\section{Phenotypic Characterization of Staphylococcus aureus}

Table (1) Number of Staphylococcus aureus isolates according to their source in the hospitals.

\begin{tabular}{|l|c|c|}
\hline Type of sample & $\begin{array}{c}\text { Number of } \\
\text { samples }\end{array}$ & $\begin{array}{c}\text { Number and percentage of } \\
\text { staphylococcus aureus }\end{array}$ \\
\hline Hospital staff nasal swabs & 50 & $11(22 \%)$ \\
\hline Hospital Air Current & 80 & $17(21 \%)$ \\
\hline Hospital surfaces & 35 & $8(22 \%)$ \\
\hline Hospital instruments & 85 & $14(16 \%)$ \\
\hline Total & 250 & $50(20 \%)$ \\
\hline
\end{tabular}




\section{JMSCR Vol||04||Issue||08||Page 11922-11930||August}

From Table (1) we can see the distribution of staphylococcus aureus isolates according to their source in the hospital and we can find that the hospital air current and the hospital instrument represented the highest source of Staphylococcus aureus isolation followed by hospital- staff nasal swabs and the test source of isolation was the hospital surface.

\section{Detection of methicillin resistant Staphylococcus aureus.}

Cefoxitin (fox) $30 \mathrm{mg}$ discs were used for detection of methicillin resistance staphylococcus aureus MRSA (Table2), because cefoxitin is regarded as a potent inducer for the regulatory system covering the mec A gene $^{(5)}$.

Table (2) Methicillin resistant Staphylococcus aureus according to their clinical source by cefoxitin susceptibility test.

\begin{tabular}{|l|c|c|c|}
\hline Clinical isolate & Number & Number of MARSA & Percent \\
\hline Hospital staff nasal swabs & 11 & 8 & $72.727 \%$ \\
\hline Hospital air current & 17 & 13 & $76.47 \%$ \\
\hline Hospital surfaces & 8 & 12 & $100 \%$ \\
\hline Hospital instruments & 14 & 41 & $85.71 \%$ \\
\hline Total & 50 & $82 \%$ \\
\hline
\end{tabular}

Susceptibility to cefoxitin $30 \mathrm{mg}$ disc was determined on Muller-Hinton agar at $37^{\circ} \mathrm{C}$ using low inoculum. The cefoxitin $30 \mathrm{mg}$ disc showed $100 \%$ specificity for detection of MRSA. Interpretive criteria were:- zone diameter $<27 \mathrm{~mm}=\mathrm{MRSA}^{(5)}$.

Table (3) Antibiotic susceptibility test for MRSA isolates.

\begin{tabular}{|l|l|l|l|l|}
\hline Antibiotic & Resistance (R) & Intermediate $(\mathrm{F})$ & Sensitive(S) & Total \\
\hline Penicillin & $41(100 \%)$ & $0(0 \%)$ & $0(0 \%)$ & 41 \\
\hline Oxacellin & $40(97.5 \%)$ & $1(2.4 \%)$ & $0(0 \%)$ & 41 \\
\hline Erythromycin & $38(92.6 \%)$ & $2(4.8 \%)$ & $1(2.4 \%)$ & 41 \\
\hline Clindamycin & $12(92.2 \%)$ & $5(12.1 \%)$ & $24(58.5 \%)$ & 41 \\
\hline Kanamycin & $8(0.19 \%)$ & $3(0.07)$ & $30(73.1 \%)$ & 41 \\
\hline Vancomycin & $1(2.4 \%)$ & $0(0 \%)$ & $40(97.5 \%)$ & 41 \\
\hline Azithromycin & $35(85.3 \%)$ & $4(0.09 \%)$ & $7(0.17 \%)$ & 41 \\
\hline Chloramphenical & $10(24.3 \%)$ & $4(0.09 \%)$ & $27(65.8 \%)$ & 41 \\
\hline Tetracyclin & $9(21.9 \%)$ & $5(21.1 \%)$ & $27(65.8 \%)$ & 41 \\
\hline Cefoxitin & $41(100 \%)$ & $0(0 \%)$ & $0(0 \%)$ & 41 \\
\hline
\end{tabular}

From table (3) It was confirmed that all MRSA isolates were found to be resistant to cefoxitin (100\%) oxacillin (97.5\%), penicillin $\mathrm{G}(100 \%)$, but also expressed high degrees of resistance to macrolids (85.3\%), clindamycin $(92.2 \%)$, tetracyclin $(21.2 \%)$. 

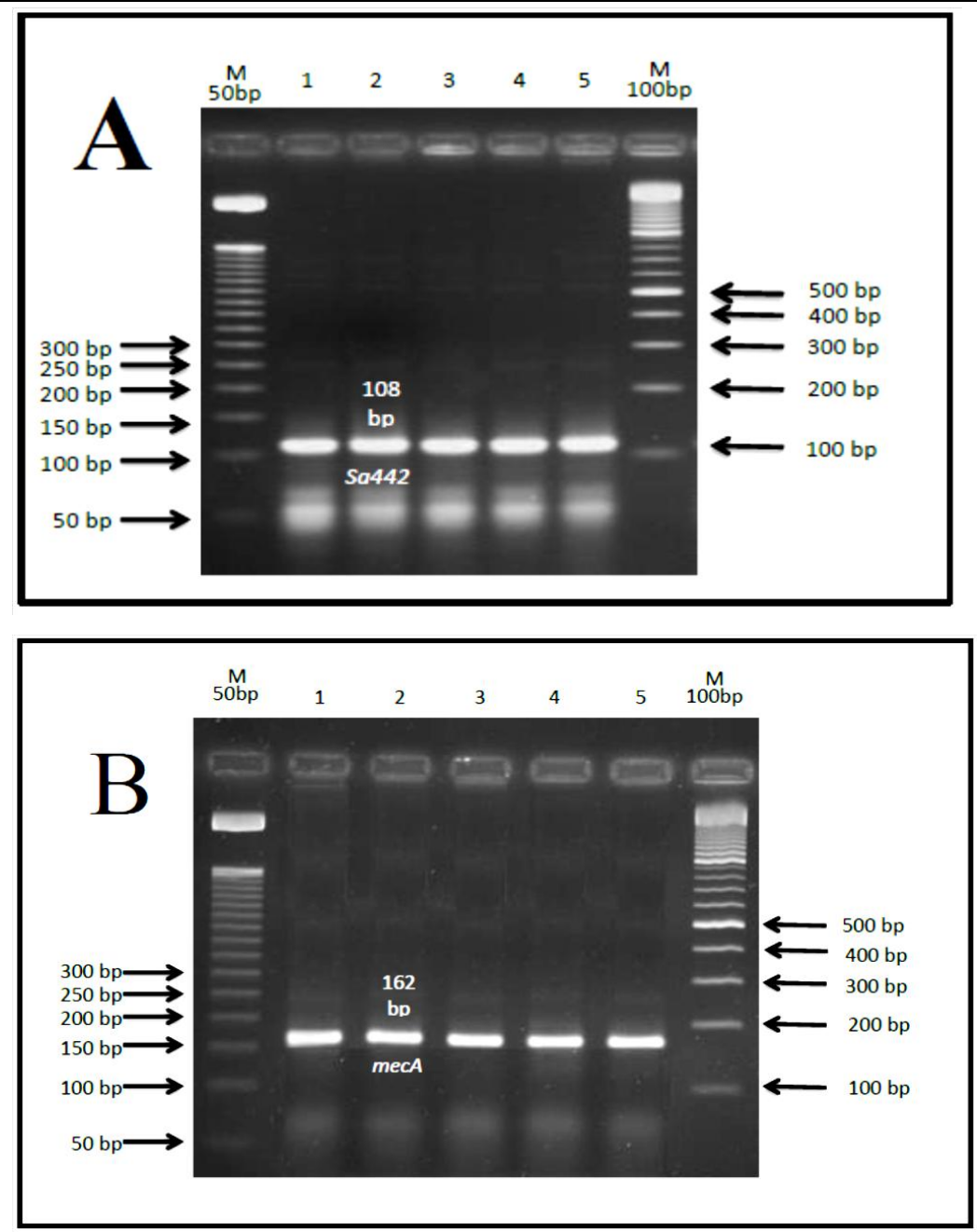

Figure(1): Conventional PCR results showing genotypic identification of MRSA isolates. A: MRSA with Staphylococcus aureus genotypic confirmation (Sa442 gene); B: MRSA with methicillin resistance detection (mecA gene). Lanes 1-5: MRSA isolates demonstrating Sa442 gene (A); Lanes 1-5: MRSA isolates demonstrating mecA gene (B); A and B: Lanes M 50bp: 50bp DNA steps ladder; Lanes M 100bp: 100bp DNA ladder; PCR products analyzed on 3\% agarose gel at $80 \mathrm{~V}$ for 1 hours.

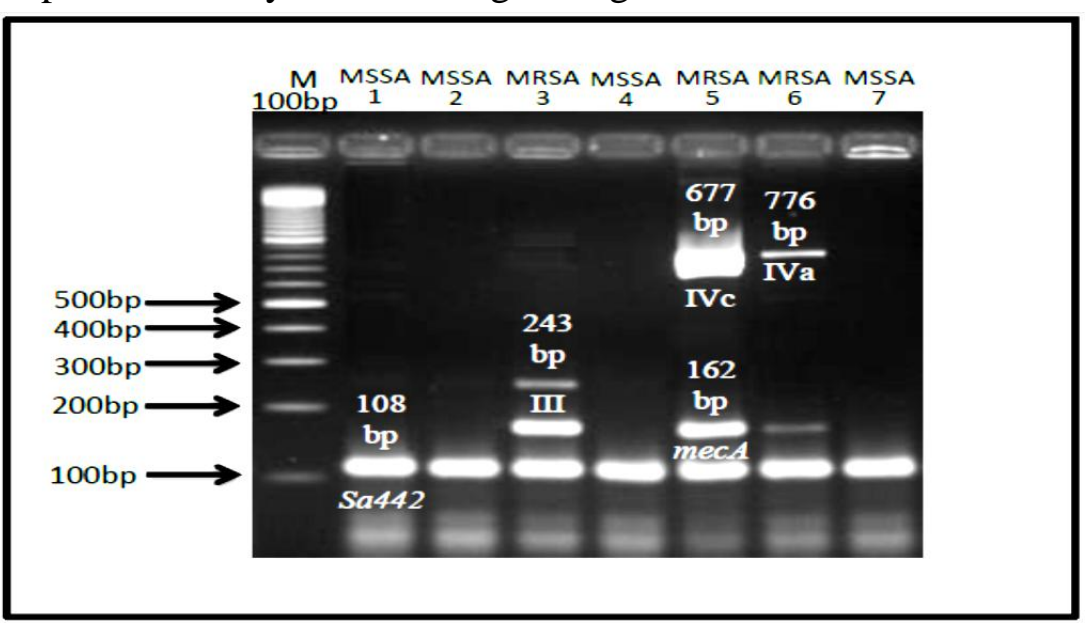

Figure (2): Multiplex PCR results showing simultaneous genotypic discrimination of MRSA from MSSA isolates. Lanes 3,5,6: MRSA isolates showing a certain SCCmec type and detected mecA gene.; Lanes 1,2,4,7: MSSA isolates showing only Sa442 gene. Lanes M 100bp: 100bp DNA ladder; PCR products analyzed on $3 \%$ agarose gel at $70 \mathrm{~V}$ for 1.30 hours. 
Table (4). Characteristics and distribution of SCCmec types and subtypes in MRSA isolates.

\begin{tabular}{|l|l|l|l|}
\hline SCCmec types & $\begin{array}{l}\text { HA or CA- } \\
\text { MRSA }\end{array}$ & $\begin{array}{l}\text { Length size } \\
(\mathrm{bp})\end{array}$ & $\begin{array}{l}\text { MRSA Isolates } \\
\text { N=32 } \\
\text { No (\%) }\end{array}$ \\
\hline SCCmec type I & Not detect & 613 & - \\
\hline SCCmec type II & HA-MRSA & 287 & - \\
\hline SCCmec type III & HA-MRSA & 243 & $5(15.6)$ \\
\hline SCCmec type IV & CA-MRSA & - & $23(71.9)$ \\
\hline SCCmec IV subtypes & & 776 & $19(59.4)$ \\
\hline SCCmec type IVa & CA-MRSA & - \\
\hline SCCmec type IVb & Not detect & 1000 & $2(6.3)$ \\
\hline SCCmec type IVc & CA-MRSA & 677 & - \\
\hline SCCmec type IVd & Not detect & 1242 & $2(6.3)$ \\
\hline SCCmec type IVh & CA-MRSA & 663 & $3(9.4)$ \\
\hline SCCmec type V & CA-MRSA & 325 & $1(3.1)$ \\
\hline $\begin{array}{l}\text { Multibands } \\
\text { SCCmec type }\end{array}$ & \multicolumn{5}{|l|}{} \\
\hline $\begin{array}{l}\text { Multibands } \\
\text { SCCmec type II and V }\end{array}$ & Unidentified & $287+325$ & Is \\
\hline Total & 32 & & \\
\hline
\end{tabular}

From tabel (4) the types SCCmec I,II,III,IV,V were type I is not detect and suptype IV is(Iva,IVb,IVc,IVd,IVh) were IVb and IVd not detect.

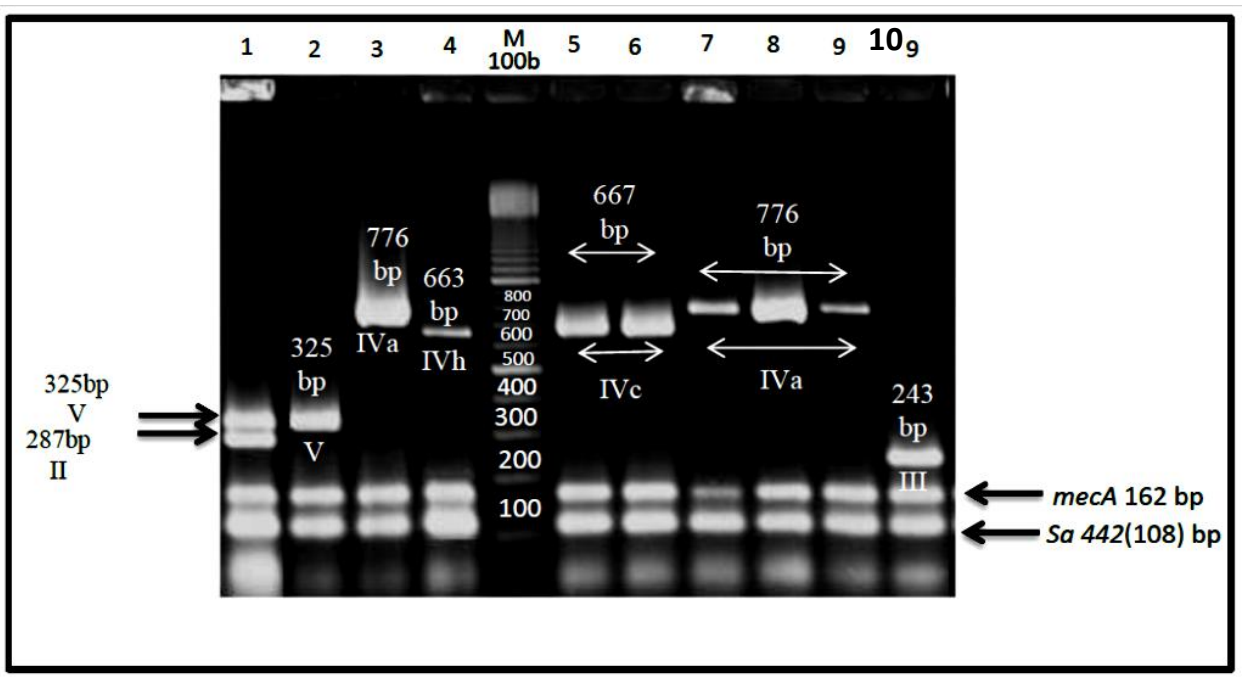

Figure (3): Multiplex PCR results identifying types and IV subtypes of SCCmec element with simultaneous detection of Sa442 and mecA genes of MRSA isolates. Type III: Lanes 10; Type IVa: lanes 7-9 and 2; Type IVc: lanes 5-6; Type IVh: lane 4, Type V: lane 2; Multiband SCCmec type II and V; Lane M100bp: 100bp DNA ladder; PCR products analyzed on $3 \%$ agarose gel at $70 \mathrm{~V}$ for 1.30 hours. 


\section{Discussion}

Evaluation of antibiotic susceptibility test: MRSA isolated is Known to have a remarkable genetic versatility, which allows for the adaptation to the present of antibiotics, such that many isolated can be multiresistant to several classes of antibiotics ${ }^{(6)}$.

In the present study one aim is to find out the resistant profile of the MRSA isolates.

From table (3) It was confirmed that all MRSA isolates were found to be resistant to cefoxitin (100\%) oxacillin (97.5\%), penicillin $\mathrm{G}(100 \%)$, but also expressed high degrees of resistance to macrolids $(85.3 \%)$, clindamycin $(92.2 \%)$, tetracyclin $(21.2 \%)$.

As a result of erythromycin and Azithromycin widespread use for treatment of Staphylococcal infections in Najaf province and in whole of Iraq, the level of resistance in MRSA isolates was high in this study.

Vancomycin is almost universally accepted as the drug choice for treatment of MRSA infection

(7).According to this, all Staphylococcus aureus isolates with Vancomycin resistance should be reported to public health and infection control committee immediately.

The first clinical Vancomycin resistant Staphylococcus aureuas was detected from a dialysis patient in USA in $2002^{(8)}$.

The possible emergence of VRSA may be due to a building of selective pressure of vancomycin ${ }^{(9)}$.

There are about three reports of emergence of VRSA from Iraq ${ }^{(10,11) .}$ and one report in Najaf

\section{Genotypic characterization of Methicillin resistant Staphylococcus aureus.}

In the current study, $\mathrm{Sa} 442$ gene detection was done in all MRSA isolates for confirmation of Staphylococcus aureus genotype, which is concerned as unique to Staphylococcus aureus (12). All biochemically detected MRSA isolates were also evaluated for the presence mecA gene (determinant of

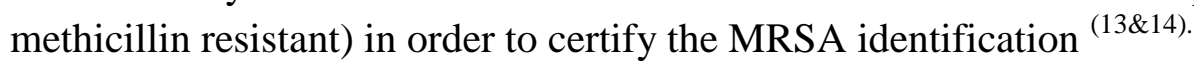

The results of present single target PCR for $S a 442$ and mecA genes revealed the expected size of fragment band; 108bp (Fig.1.A) and 162bp (Fig.1.B) respectively. The Sa442 PCR results showed that all the 41isolates were positive for Sa442 gene with $100 \%$ concordant with Vitec2 results, giving rise to documentation that all isolates were Staphylococcus aureus. While mecA PCR results found 32 out of 41 (78\%) of biochemically detected MRSA isolates were positive for mecA gene and certified as MRSA and the 9 remaining isolates (22\%) were mecA-negative and identified as Methicillin Sensitive Staphylococcus aureus (MSSA). This confirmed the ability of mecA PCR detection in accurate differentiating MRSA from MSSA isolates ${ }^{(13 \& 14) .}$ found that $47.4 \%$ and $71 \%$ of clinical isolates from An Najaf hospitals were MRSA and MSSA respectively depending on mecA PCR detection.

Molecular typing of MRSA-SCCmec element

Among 41 isolates, 32 MRSA isolates were mecA-positive with certain type or subtype of SCCmec with exception of one was multiband. While the remaining 9 MSSA isolates were mecA-negative and positive for Sa442 gene without any SCCmec typing Fig.(2). The mecA and Sa442 genes results were 100\% concordant with that obtained by conventional PCR results, demonstrating the simultaneous ability of the current MPCR to discriminate MRSA from MSSA isolates. Therefore, M-PCR assay included the mecA target may play a scientific role in this differentiation of MRSA from $\operatorname{MSSA}^{(13) \cdot}$ target may play a scientific role in this differentiation of MRSA from MSSA ${ }^{(13) .}$

The majority of MRSA isolates (71.9\%) carried SCCmec type IV which is regarded as community-acquired MRSA (CA-MRSA) that showed highest SCCmec distribution compared to the commonly isolated hospitalacquired strains (HA-MRSA) SCCmec types III (15.6\%), while CA-MRSA type V was (9.4\%) and only one isolate (3.1\%) was not-type able with multiple bands for types II and V, at the same time HA-MRSA SCCmec types I and II were not detectable (Fig 3). 
Accordingly, the present results revealed that the most current isolates are CA-MRSA (type IV and V) with predominance of SCCmec type IV in consistent with that previously reported in Najaf province in a study done by Al-Hassnawi et al, ${ }^{(21)}$ who found that most of his clinical isolates (100\%) from Najaf hospital are SCCmec type IV. Moreover, another study conducted in Hila city demonstrated that $95.8 \%$ of clinical MRSA isolates were CA-MRSA SCCmec type IV ${ }^{(15)}$ but another research detected this type was less frequently isolated (15.8\%) in Baghdad hosptials ${ }^{(16)}$. The two later studies did not find types I-III of SCCmec element among their isolates in contrast to study done by Sabri et al (2013) who observed that $36.4 \%$ of his MRSA isolates were SCCmec type III. Their rate in India and Philippines found to be much lower than other

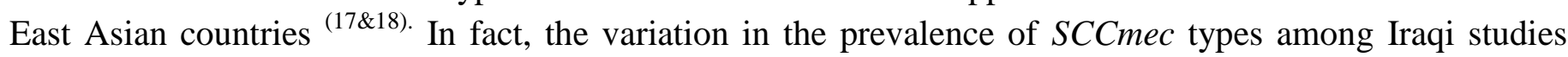
may be related to differences in the way of collecting the samples, or to hospital or community population involved as well as the difference in power and ability of PCR assays used in detection of SCCmec types. However, the increased SCCmec type IV incidence was documented worldwide and become common among hospital MRSA isolates. Among nosocomial bloodstream MRSA gathered in Brazil, 95\% of MRSA isolates were SCCmec type IV recorded very high frequency ${ }^{(19)}$. and Chen et al, ${ }^{(20)}$. reported that $40 \%$ of MRSA harbored SCCmec type IV in Twain. It is recently demonstrated that CA-MRSA has emerged within hospitals in many places of the world causing nosocomial infections.

According to the all current data obtained, the present study successfully identified the subtypes of SCCmec type IV which demonstrated that the IVa subtype was the commonest among them and detected the presence of SCCmec type IVh giving rise to the possibility of nosocomial EMRSA-15 emergence in our country. Regarding the fact that the most common MRSA strains in hospitals may become CA-MRSA strains in replacing of HA-MRSA strains ${ }^{(21)}$ the rapid and reliable molecular typing method of SCCmec element involving most known types and subtypes with simultaneous methicillin resistance and Staphylococcus aureus genotypic identification as single M-PCR assay done in the present study should be applied. In order to be implemented in the rapid and precise detection of MRSA stains that assisted in the successful treatment, epidemiological identification and suppression of CA-MRSA strains outbreaks to the hospital.

\section{Conclusions}

Polymerase chain reaction is the golden slandered for identification of methicillin resistant Staphylococcus aureus MRSA. The SCC mec type IV was the most dominant among SCCmec genotypes of MRSA strains that were isolated from hospitals in the present study.

\section{Recommendations}

Vancomycin resistant staphylococcus aureas (VRSA) should be taken in consideration when we are working with hospital cross infection.

Further studies on large scale should be performed in order to study MRSA in the whole country.

Antibiotic prescribing policy should be put under observation and guidenece inside and outside hospitals.

\section{References}

1. Gould, I. M., David, M. Z., Esposito, S., Garau, J., Lina, G., Mazzei, T. and Peters, G. New insights into methicillin- résistant Staphylococcus aureus pathogenèses, trématent and résistance. Int. J. Antimicrob. Agents., 39: 96-104. (2012).

2. Shittu,A.O.,Nubel, U., Udo, E.E. Lin,J.\&Gaogakwe,S.(2009). Characterization of methicillinresistant Staphylococcus aureus (MRSA) isolates from hospitals in KwaZulu-Natal (KZN) province, Republic of South Africa .J.Med. Microbiol.58(9):1219-1226. .(2009). 
3. Von-Eiff,C., Becker, K.,Stammer, H.\&Peters,GNasal carriage as a source of Staphylococcus aureus bacteremia .N.Engl.J.Med.344(1):11-16. .(2001).

4. Swenson,J.M.; Lonsway, D.;McAllister,S.; Thompson, A.;Jevitt. L.and patel, J.B. Detection of mecA-mediated Resistance Using Cefoxitin Disk Diffusion (DD) in a Collection of Staphylococcus aureus Expressing Borderline oxacillin MICs. Diagn.Microbiol. Infect. Dis; 58:33-9. (2007).

5. Felten, A., Grandry, B., Lagrange, P.H. and Casin, I. Evaluation of three techniques for detection of low-level methicillin-resistant Staphylococcus aureus: a disk diffusion method with cefoxitin and moxalactam, the Vitek 2 system and the MRSA-screen latex agglutination test. J. Clin. Microbiol., 40(8): 2766. (2002).

6. Akindele, A.A., Adewuyi, I.K., Adefioye, O.A., Adedokun, S.A. and Olaolu, A.O. Antibiogram and $\beta$-lactamase production of Staphylococcus aureus isolates from different human clinical specimens in a tertiary hospital institution in Ile-ife, Nigeria. American-Eurasian. J. Scien. Res., 5: 230-233. (2010).

7. Zarakolu, P., Metan, G., Altun, B. and Unal, S. Antimicrobial susceptibility, inducible macrolidelincosamide-streptogramin B, and clonal diversity patterns of nosocomial methicillin-resistant Staphylococcus aureus strains isolated in Hacettepe university adult hospital. Turk. J. Med. Sci., 39(5): 783-789. (2009).

8. Bokarewa, M. I.; Jin, T. and Tarkowski. A Staphylococcus aureus: staphylokinase. Int.J. Biochem Cell Biol 38:5:504-9. (2006).

9. Kaleem, F., Usman, J., Sattar, A., Amanat, S.T., Hassan, A., Omair, M., Khalid, A. and Riaz, M. Current status of vancomycin susceptibility against methicillin resistant Staphylococcus aureus strains: a study at two tertiary care hospitals of Pakistan. Afr. J. Microbiol. Res., 6(33): 6243-6246. (2012).

10. Mohammed, D.A. and Khder, D.S. Distribution of insertion sequences in Tn1546 element in vancomycin-resistant Staphylococcus aureus (VRSA) in Sulaimani, Kurdistan of Iraq. J. Comput. Biol. Bioinform. Res., 3(4): 42-46. (2011).

11. Al-Marjani, M.F. and Hadi, A.S. Partial nucleotide sequencing of the mecA gene of vancomycinresistant Staphylococcus spp. Isolated in Baghdad, Iraq. Int. J. Adv. Res., 1(6): 109-115. (2013).

12. Ghaznavi-Rad, E., Shamsudin, M. N., Sekawi, Z., Khoon, L. Y., Aziz, M. N., Hamat, R. A., Othman, N., Chong, P. P., van Belkum, A. \& other authors. Predominance and emergence of clones of hospitalacquired methicillin-resistant Staphylococcus aureus in Malaysia. J Clin Microbiol 48, 867872. (2010) b

13. Zhang, K., J. A. McClure, S. Elsayed, T. Louie, and J. M. Conly. Novel multiplex PCR assay for characterization and concomitant subtyping of staphylococcal cassette chromosome mec types I to V in methicillin-resistant Staphylococcus aureus. J. Clin. Microbiol. 43:5026-5033. (2005).

14. Al-Mohana, A.M., Al-Charrakh, A., Nasir, F.H. and Al-Kudhairy, M.K. Community-acquired methicillin-resistant Staphylococcus aureus (CA-MRSA) carrying mecA and Panton-Valentine leukocidin pvl genes isolated from the holy shrine in Najaf, Iraq. J. Bacteriol. Res., 4(2): 15-23. (2012).

15. AL-Hassnawi ,H.H., AL-Charrakh, A.H. and ALKhafaji, J.K.Antibiotic resistance patterns of community acquired methicillin resistance Staphylococcus aureus (CA-MRSA) in AL-Hilla.Iraq. Kerbala. j.Pharma . Science.4:91-102. .(2012)

16. AL-Kadmy. A genetic study to differential hospital methicillin resistant Staphyloccus aureus (HAMRSA) and community acquired methicillin resistance Staphylococcus aureus (CA-MRSA) isolatefrom clinical cases in Iraq hospitals. Mintage.J.pharma.med.Scie.2(3):57-62. (2013). 
17. Chamber, H.FPathogenesis of Staphylococcus infection: A Manner of Expression.J.I.D.199:291-293. .(2009).

18. Corkill, J. E., J. J. Anson, P. Griffiths, and C. A. Hart. Detection of elements of the staphylococcal cassette chromosome (SCC) in a methicillinsusceptible (mecA gene negative) homologue of a fucidin-resistant MRSA. J. Antimicrob. Chemother. 54:229-231.( 2004).

19. Derycke L,Perez-Novo CA,Van Crombruggen K,Corriveau M, Bachert C Staphylococcus aureus and Chronic Airway Disease. WAO Journal.;3:223-8. (2010).

20. Derycke L,Perez-Novo CA,Van Crombruggen K,Corriveau M, Bachert C(2010). Staphylococcus aureus and Chronic Airway Disease. WAO Journal.;3:223-8.

21. Stranden A, Frei R, Adler H, Flückiger U, Widmer A. Emergence of SCCmec type IV as the most common type of methicillin-resistant Staphylococcus aureus in a university hospital. Infection 2009; 37: 44-8. doi: 10.1007/s15010-008-7430-7 